\title{
Dangerous Liaisons? Governments, companies and Internet governance
}

\author{
Francesca Musiani \\ MINES ParisTech, France, francesca.musiani@mines-paristech.fr
}

Published on 17 Feb 2013 | DOI: 10.14763/2013.1.108

\begin{abstract}
Private actors in the information technology sector are currently playing an increasingly important role in content mediation, as well as in regulation of online forms of expression, with implications for both internet rights and economic freedom. The "privatisation of internet governance" (DeNardis, 2010), is not a new dynamic; however, in a scenario in which users are taking advantage of increasingly sophisticated technology, the centralisation and concentration characterising today's most widespread internet services are contributing to the accentuation of this tendency. The 'inherently political' qualities of search engine algorithm development, video content removals, blocking of domain names - actions that originate and rest with the private sector's handling of the internet's infrastructure - should not be neglected in our assessment of the field of internet governance today.
\end{abstract}

Keywords: Internet governance, Regulation, Privatisation, Private sector, Infrastructure, Infomediary

\section{Article information}

Received: 18 Feb 2013 Reviewed: 27 Feb 2013 Published: 17 Feb 2013

Licence: Creative Commons Attribution 3.0 Germany

Competing interests: The author has declared that no competing interests exist that have influenced the text.

URL:

http://policyreview.info/articles/analysis/dangerous-liaisons-governments-companies-and-internet-go vernance

Citation: Musiani, F. (2013). Dangerous Liaisons? Governments, companies and Internet governance. Internet Policy Review, 2(1). https://doi.org/10.14763/2013.1.108

Private actors in the information technology sector are currently playing an increasingly important role in content mediation, as well as in regulation of online forms of expression, with implications for both internet rights and economic freedom.

The latest Google Transparency Report (Google, 2013) released on January 24, 2013, sends a clear and somewhat disquieting message to the advocates of a more transparent internet governance worldwide. Several governments in the European Union are submitting a steadily increasing number of requests to the giant of online information search, with two purposes: the acquisition of several types of sensitive information about internet users - including their IP addresses, browsing and navigation history, and email communications - and removal of specific content. This "dramatic" (EDRi-gram, 2013) increase raises questions about the very 
nature of the relationship, or partnership, between political institutions and the 'majors' of the IT sector. This is true for online privacy, but also for the legitimacy and transparency of the net's gatekeepers and overall, for internet governance - an ongoing multi-stakeholder development of shared principles, norms, rules, decision making procedures and programmes, that shape the evolution and utilisation of the internet.

\section{PRIVATISATION OF INTERNET GOVERNANCE}

Quoted by the BBC, Privacy International's head of international advocacy, Carly Nyst, says: "The information we hand over to companies like Google paints a detailed picture of who we are - from our political and religious views to our friendships, associations and locations. Governments must stop treating the user data held by corporations as a treasure trove of information they can mine whenever they please, with little or no judicial authorisation." (BBC, 2013) While privacy concerns that may derive from third party access of such information are perhaps the first that come to mind, this article focusses mainly on the second most relevant result from the report: the fact that private companies such as Google are increasingly mobilised or solicited by governments to act as content mediators and de facto core actors in internet governance. The Report's statistics are the latest - but not the last - illustration of how internet governance is increasingly being handled by private companies, and of industry's "heightened role in regulating content and governing expression as well as responding to restrictions on expression" (DeNardis, 2012), most often under mandate or instructions of governments.

This phenomenon, which internet governance scholar Laura DeNardis has recently and concisely described as the "privatisation of internet governance" (DeNardis, 2010), is not a new dynamic, inasmuch as industry and the technical community have always played a fundamental role in how the internet is designed and managed, be it by contributing to standard-setting or infrastructure management. However, in a scenario in which users are taking advantage of increasingly sophisticated technology, the centralisation and concentration characterising today's most widespread internet services are contributing to the accentuation of this tendency: "a small number of internet service providers concentrate a large part of the people's online activities and time, their personal data and social networks, they exercise a considerable power on their users through the mere application of their terms of uses. [...] Some services even play roles that used to be the monopoly of states, such as guaranteeing their users' identity or maintaining social order online" (Arsène, 2012).

Indeed, as the journalist and co-founder of Global Voices Online, Rebecca MacKinnon, has pointed out, the millions of users - and the pervasiveness in their lives - of the Googles and Facebooks of today make these companies comparable to virtual "countries", traditionally coinciding with the scope and jurisdiction of nation states (MacKinnon, 2012). There are indications that "various types of private ordering increasingly perform internet governance functions [...] Private industry internet governance often takes place at the level of infrastructure management, an area fairly invisible to the public. In other areas, the role of private industry in ordering the flow of information over the internet is much more visible and well understood" (DeNardis, 2010). This is certainly the case for content removal actions, requested by governments or intergovernmental organisations and enacted by private companies, which constitute most of Google's Transparency Report - and prominently feature EU states. 


\section{INTERNET INTERMEDIARIES AS INFORMATION GATEKEEPERS}

The extent of the control (and as a consequence, the responsibility vis-à-vis the users) of the great information services, intermediaries and gatekeepers of today's internet on usergenerated, online-published content has been particularly evident in September 2012, when Google, owner of the very popular video streaming service YouTube, decided to block access to the infamous video Innocence of Muslims, ridiculing the Prophet Muhammad, in two of the countries that have experienced severe upheavals, Egypt and Libya - while at the same time choosing not to remove it completely from its website. In that occasion, Peter Spiro, a professor of law at Temple University, in the United States, had declared to the New York Times: "Google is the world's gatekeeper for information, so if Google wants to define the First Amendment to exclude this sort of material then there's not a lot the rest of the world can do about it [and] it makes this episode an even more significant one if Google broadens the block" (Cain Miller, 2012). Indeed, in this prominent case and in all of those mentioned in the recent transparency report, Google's actions as a content mediator demonstrate the "court-of-law-like powers of internet information intermediaries, de facto able to decide what content remains public, and what is taken out" (Musiani, 2012).

The crucial role of the private sector in internet governance has also come to the attention of the media on the occasion of the 2010 WikiLeaks U.S. diplomatic cables controversy. EveryDNS suspended its domain name resolution service, impeding the correct functioning of one of the internet's "phone books" for the WikiLeaks website and thus effectively preventing the nontechnically savvy public around the world from accessing it, eliciting reactions such as "This has come about through the actions of the U.S. Government. The government's statements about Wikileaks have forced companies to analyze their Terms of Service [...] In the name of security, our government has decided to force others to block information that they fear would have terrible, terrible impacts" (Williams, 2010).

Amazon blocked its hosting of the wikileaks.org website after an inquiry by the U.S. Senate Homeland Security Committee, prompting Ryan Calo, a lecturer at Stanford University's Center for Internet and Society, to declare to Reuters that under U.S. law, Amazon would likely have been shielded from any possible prosecution by the government: "It would set a dangerous precedent were companies like Amazon to take down things merely because the senator or another government entity started to ask questions about them" (Pelofsky, 2010).

Online financial services firms PayPal, Visa and MasterCard blocked the financial flow of money to WikiLeaks.

Taken together, these measures de facto cancelled WikiLeaks' visibility on the internet and prevented public access to 'leaked' content. Regardless of the delicate or classified status of that particular content, the WikiLeaks case raises broader questions about the amount of control that internet companies can exert alongside governments on what should, and should not, be publicly and freely expressed online, and highlights the difficult positions that content platforms are sometimes put in - because of the responsibility that their "privileged gatekeeper status" entails. 


\section{INFORMAL DIMENSIONS OF INTERNET GOVERNANCE}

The increasing importance of the private sector in internet governance should not be exclusively read in terms of its potential restrictions to freedom of expression, threats to internet users' privacy, and accountability to the public. The role of private industry is also, and historically, a positive one of market-spurred innovation and technical effectiveness in networked distribution, communication and interaction (DeNardis, 2010).

At the same time, "network providers deploy network-address translators that let several devices share the same address. To protect their networks against attacks, organizations put firewalls that block potentially harmful applications at the borders of their private networks. To increase their profits, network providers use technologies that enable them to identify and control the applications and the content passing through their networks" (Van Schewick, 2011).

All of these actions, in addition to the uses of internet infrastructure for content mediation, as discussed above, are an integral part of internet governance, albeit a more informal one. These private actions are often de-prioritised in internet governance discourse to make way for more institutionalised or forms of governance that are politically more traditional: governments, international and supranational organisations, multi-stakeholder fora, and organised civil society.

As information studies scholar Michel van Eeten interestingly pointed out, "A very large part of the internet governance field's scholarly literature tends to focus almost exclusively on these formal international institutions involved in explicit discussions of the global governance of the internet. On the other hand, the term 'internet governance' is not normally applied to studies of many real-world activities and problems that play a crucial role in shaping and regulating the way the internet really works" (Van Eeten, 2009).

\section{INTERNET GOVERNANCE DISCOURSE IN EUROPE}

A quick 'mapping' glance at internet governance at the European regional level seems to confirm the institutional orientation in the political and scholarly treatment of the internet governance field.

An online search on "Europe" and "internet governance" on Google and Yahoo!, for example, returns query results that are heavily centred on the activities of the Council of Europe (CoE) in this field; activities that are framed in the broader macro-area of 'Human Rights and the Rule of Law', implicitly according priority to the ways in which the existing and established international law and human rights system is addressing these emerging topics (CoE, 2013a). Zooming in some more, the most recent news on display concerns the CoE's collaborations with other international or supranational organisations, from the United Nations Educational, Scientific and Cultural Organization (UNESCO) to the Internet Corporation for Assigned Names and Numbers (ICANN), from the Internet Governance Forum (IGF) to the European Broadcasting Union (EBU) (CoEa, 2013).

One needs to go back to April 2012 to find a notice that implicitly addresses private governance: the CoE's adoption of recommendations for search engines to "increase transparency in the way access to information is provided, in particular the criteria used to select, rank or remove search 
results" (CoE, 2013b). The European Dialogue on Internet Governance, an annual convening of an "informal and inclusive discussion and exchange on public policy issues related to Internet Governance (IG) between stakeholders from all over Europe” (IFLA, 2013), whose next meeting will be held in Lisbon, Portugal on June 20 and 21 (EuroDIG, 2013), is also prominently featured in search results on European internet governance, as well as the core European Union governing instances, the Parliament and the Commission.

\section{INTERNET GOVERNANCE TO MAKE DANGEROUS LIAISONS EXPLICIT}

The traditional instruments of the international political and legal system, such as conventions, treaties, charts and intergovernmental agreements, certainly hold a crucial role in internet governance, both as an arena of political experimentation and a field of study. Still, the "inherently political" qualities of search engine algorithm development, video content removals, blocking of domain names - actions that originate and rest with the private sector's handling of the internet's infrastructure - should not be neglected in our assessment of the field of internet governance today.

This is of particular importance, as these actions are often enacted in collaboration or under the mandate of governmental and supranational institutions, in dangerous liaisons whose details, conventions and compromises often escape the public radar. As legal scholar Kevin Werbach reminds us, quite originally within his field, "Two forces are in tension as the internet evolves. One pushes toward interconnected common platforms; the other pulls toward fragmentation and proprietary alternatives. Their interplay drives many of the contentious issues in cyberlaw, intellectual property, and telecommunications policy, including the fight over "network neutrality' for broadband providers, debates over global internet governance, and battles over copyright online" (Werbach, 2009).

With possible implications for the resurgence of proprietary values, the diminishment of internet governance transparency, and the use of internet governance techniques for a competitive advantage on the market (DeNardis, 2012), the private sector is today at the crossroads of this tension, and plays a crucial role in how it will unfold in the close-future internet governance at the local, regional and global levels. 


\section{REFERENCES}

Arsène, S. (2012). The Impact of China on Global internet Governance in an Era of Privatized Control. Chinese internet Research Conference. Los Angeles.

British Broadcasting Corporation. (2013). "Google transparency report shows rise in data requests”, http://www.bbc.co.uk/news/technology-21169162

Cain Miller, C. (2012). "As Violence Spreads in Arab World, Google Blocks Access to Inflammatory Video”, The New York Times, September 13.

http://www.nytimes.com/2012/o9/14/technology/google-blocks-inflammatory-video-in-egyptand-libya.html?_r=o

Council of Europe. (2013a). Human Rights and the Rule of Law.

http://www.coe.int/t/dgi/default_en.asp

Council of Europe. (2013b). Information Society. http://www.coe.int/t/informationsociety/

DeNardis, L. (2012). “The Turn to Infrastructure for Internet Governance”, Concurring

Opinions, 2012,

http://www.concurringopinions.com/archives/2012/o4/the-turn-to-infrastructure-for-internet -governance.html

DeNardis, L. (2010). The Privatization of Internet Governance. Fifth GigaNet Annual Symposium/Yale Information Society Working Paper.

European Digital Rights (EDRi). (2013). EDRi-gram newsletter 11.2, 30 January. https://edri.org/edrigramnumber10-12google-transparency-report-increasedgovt-surveillance/

European Dialogue on Internet Governance. (2013.) European Dialogue on Internet Governance. http://www.eurodig.org/

Google. (2013). Google Transparency Report http://www.google.com/transparencyreport/removals/government/

International Federation of Library Associations and Institutions (IFLA). (2013). EuroDIG. http://www.ifla.org/events/eurodig

MacKinnon, R. (2012). Consent of the Networked: The Worldwide Struggle for internet Freedom. New York City: Basic Books.

Musiani, F. (2012). "Google and Video Blocking: Control (and Responsibility) of Information Intermediaries on the internet", Intervention at the Religion, Freedom of Expression, and Outrage Panel, October 1, 2012, Georgetown University, http://adam.hypotheses.org/1383

Pelofsky, J. (2010). “Amazon Stops Hosting WikiLeaks Website”, Reuters, http://www.reuters.com/article/2010/12/02/us-wikileaks-amazon-idUSTRE6Bo5EK20101202

Van Eeten, M. (2009). "Where is the Governance in Internet Governance?”, Fourth Annual GigaNet Symposium, Sharm-el-Sheikh, Egypt, November.

Van Schewick, B. (2011). Internet Architecture and Innovation. Cambridge, MA: The MIT Press. 
Werbach, K. (2009). "The Centripetal Network: How the internet Holds Itself Together, and the Forces Tearing it Apart”, University of California Davis Law Review, 42 (2), 343-412.

Williams, A. (2010). "Wikileaks Loses Its DNS Service”, Readwrite.com, http://readwrite.com/2010/12/o2/wikileaks-loses-its-dns-servic 